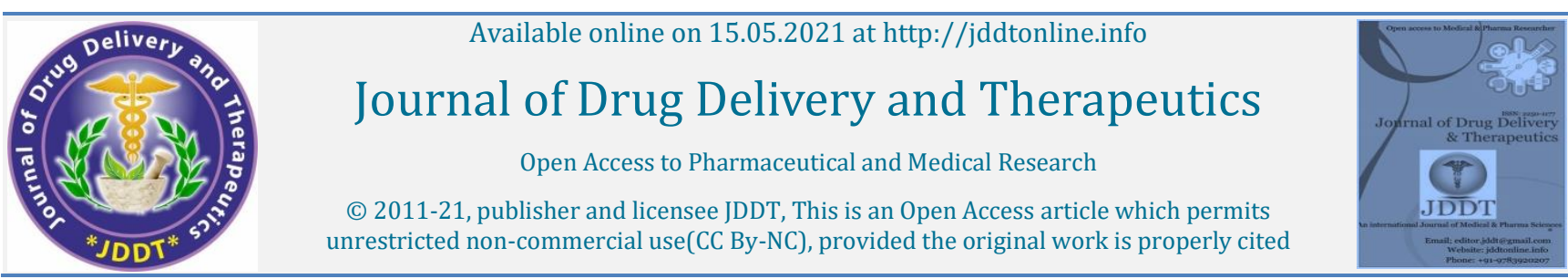

(C) 2011-21, publisher and licensee JDDT, This is an Open Access article which permits
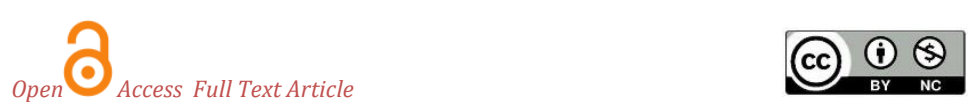

Review Article

\title{
Formulation Development Studies for Sterile Dosages: A Comprehensive Review
}

\author{
Govind Raju. N1, Shishir Ojha², Sumit Kumar Roy ${ }^{3}$, Amit Kori ${ }^{4}{ }^{*}$ Anjaneyulu Vinukonda ${ }^{2}$ \\ ${ }^{1}$ AGM - FR\&D; Maiva Pharma Pvt Ltd, SIPCOT industrial complex, Hosur, India \\ ${ }^{2}$ Alembic Pharmaceuticals Ltd, Vadodara, India \\ ${ }^{3}$ Cipla Limited R\&D Centre, Mumbai, India \\ ${ }^{4}$ PAR Pharmaceutical; An Endo International Company, Indore, India
}

\section{Article Info:}

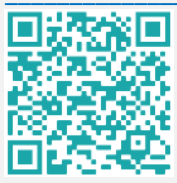

\section{Article History:}

Received 23 March 2021:

Review Completed 21 April 2021

Accepted 30 April 2021;

Available online 15 May 2021

\section{Cite this article as:}

Raju N G, Ojha S, Roy SK, Kori A, Vinukonda A, Formulation Development Studies for Sterile

Dosages: A Comprehensive Review, Journal of Drug

Delivery and Therapeutics. 2021; 11(3):122-125

DOI: http://dx.doi.org/10.22270/jddt.v11i3.4743

\section{Abstract}

Sterile generic dosage development requires that specific critical quality attributes be considered and evaluated, regardless of the route of delivery or the type of registration application. The review briefed with an overview of Pharmaceutical Development study requirements. Each of the various stages of studies like Compatibility with the packaging materials, manufacturing vessels, processing aids, MOCs, Filters, Tubing's and Gaskets also with special studies to be conducted as part of Regulatory Submission, process considerations. Thus, the chapter offers the formulator an overview of the foundational principles associated with formulation development /Pre-formulation studies of sterile products.

Keywords: Pharmaceutical Development, Compatibility, Studies, Hold time.

*Address for Correspondence:

Dr. Anjaneyulu Vinukonda, Team Lead- Manufacturing science \& Technology, Alembic Pharmaceuticals Ltd. Vadodara, India

\section{Chemical stability of Drug substance in Formulation:}

Stress testing of Formulation was performed to study its impurity profile, degradation pathway and to facilitate the development of a stability-indicating method. In addition, knowledge obtained from the forced degradation studies was used during formulation and process design and development to prevent impurities from being generated.

Formulation as such:

- Thermal degradation studies $\left(60^{\circ} \mathrm{C}\right.$ for $24 \mathrm{Hrs}$. $)$

- Photolytic degradation studies as per ICH Q1B

- Hydrolytic degradation studies $\left(80^{\circ} \mathrm{C}\right.$ in water for 8 Hrs.)

- Acidic degradation studies (with $5 \mathrm{~mL}$ of $0.5 \mathrm{M} \mathrm{HCL}$ at $25^{\circ} \mathrm{C}$ for $5-10$ minutes)

- $\quad$ Alkaline degradation studies (with $0.5 \mathrm{~mL}$ of $0.5 \mathrm{M} \mathrm{NaoH}$ at $25^{\circ} \mathrm{C}$ for 10 minutes)

- $\quad$ Peroxide degradation studies (with $1 \mathrm{~mL}$ of $10 \% \mathrm{H}_{2} \mathrm{O}_{2}$ at $25^{\circ} \mathrm{C}$ for $2-5$ minutes)
Based on the forced degradation results of the drug product, it can be concluded that the drug product undergoes significant degradation under Specific conditions.

Ex. Peroxide degradation $>$ Light degradation $>$ Acidic degradation $>$ Alkaline degradation $>$ Thermal degradation.

Inference: Based on the study results, API/Product related storage and manufacturing conditions will be proposed for further batches.

\section{Effect of Dissolved Oxygen (D0) \& Headspace Oxygen on Product Stability:}

Effect of DO \& $\mathrm{HSO}_{2}$ directly impacts the drug product CQA's i.e. Assay, Related substances, considering the oxidative degradation as per forced degradation data. Hence, Comparative studies has to be performed for different presentations/fill volumes with different DO level (Ex. $<1 \mathrm{PPM} /$ ) \& $\mathrm{HSO}_{2}$ content (Ex. $<2 \% /<10 \%$ ) vs. without control (As such filled vial) on drug product during lab scalestability. As per the stability outcome DO level and $\mathrm{HSO}_{2}$ content for final filled vials to be recommended, in order to control the oxidative degradation related impurities upon stability. Hence, during compounding nitrogen sparging/ blanketing to be done and during filling flashing of nitrogen to be done in to the vials before and after filling and before stoppering to maintain DO level and $\mathrm{HSO}_{2}$. 
Inference: Based on the study results DO limit / Headspace requirement limit of respective product shall be proposed for further batches.

Overages: No overages are recommended, if used Justification to be included as per 3.2.P.2.2.21.

\section{Order of Addition studies:}

A study to be conducted to evaluate \& finalize the Order of addition of excipients and API during the manufacturing.Order of addition of drug and excipients has significant impact on drug product CQA's especially on Impurity level. Hence, the impact of sequential addition of excipient and API of the drug product will be studied during manufacturing of bulk solution. Based on the satisfactory results the order of addition shall be finalised.

Inference: Based on the study results, the order of addition of excipients and API during the manufacturing of respective product shall be proposed for further batches.

\section{Effect of Manufacturing Temperature on Drug Product Stability:}

A study to be conducted to evaluate the effect of manufacturing temperature during the manufacturing. Lab batches shall be manufactured at different temperatures i.e., at $2^{\circ} \mathrm{C}-8^{\circ} \mathrm{C} /$ Room temperature $\left(25^{\circ} \pm 5^{\circ} \mathrm{C}\right)$ and same to be loaded in the stability to study the effect of manufacturing temperature on drug product CQA's during stability.

Inference: Based on the study results, the manufacturing temperature will be recommended for the respective product same shall be proposed for further batches.

\section{Hold time/Manufacturing vessel compatibility:}

This study to be conducted to evaluate the manufacturing vessel MOC (SS316L) is suitable to use for bulk solution manufacturing .A bulk solution to be prepared and stored in the manufacturing vessel and with draw the samples with respective time points i.e. Initial $(0 \mathrm{Hrs}), 6 \mathrm{Hrs}, 12 \mathrm{Hrs}, 24$ Hrs, $48 \mathrm{Hrs}$ and submitted for the evaluation of drug product CQA's i.e. Description, pH, Assay, Related substances, (Sterility, BET, Bio burden will be performed on submission batch sample).

Inference: Based on the satisfactory results, the hold time will be proposed for scale-up batches/submission batches. same shall be re-verified in submission batches and Hold time recommendation for time of Bulk solution (Filtered \& Unfiltered) will be used during commercial batches.(Unfiled bulk hold time shall be considered from API addition \& Filtered Hold time shall be considered after filtration).

\section{Tubing compatibility:}

To demonstrate the physical and chemical compatibility of tubing for the transfer of bulk solution during the manufacturing process.

Static Study: A bulk solution to be prepared and stored in the proposed tubing and withdraw the samples at Initial $(0$ Hrs), $6 \mathrm{Hrs}, 12 \mathrm{Hrs}, 24 \mathrm{Hrs}, 48 \mathrm{Hrs}$, 72Hrs respectively and evaluated for drug product CQA's i.e. Description, $\mathrm{pH}$, Assay, Related substances.

Dynamic Study: A bulk solution to be prepared and passed through proposed tubing by peristaltic pump and with draw the samples with respective time like Initial (0 Hrs), $6 \mathrm{Hrs}, 12$ Hrs, $24 \mathrm{Hrs}, 48 \mathrm{Hrs}, 72 \mathrm{Hrs}$ and submitted for the evaluation of drug product CQA's i.e. Description, pH, Assay, Related substances. Ex. Platinum cured silicone tube, FEP tubing.
Inference: Based on the study results, physical and chemical compatibility of the tubing with respective product and its hold time shall be proposed for further batches at specified temperature.

\section{Filter membrane compatibility:}

A study to be conducted to evaluate the compatibility and adsorption of drug by the filter membrane used and selection. A bulk solution will be prepared and the proposed filters were added separately and withdraw the samples at Initial ( $0 \mathrm{Hrs}$ ), $6 \mathrm{Hrs}, 12 \mathrm{Hrs}, 24 \mathrm{Hrs}, 48 \mathrm{Hrs}$, 72Hrs respectively and evaluated for drug product CQA's i.e. Description, $\mathrm{pH}$, Assay, Related substances.

Ex. PVDF, PTFE, PES, PP Filters.

Inference: Based on the study results, physical and chemical compatibility of the filter with respective product and its hold time shall be proposed for further batches at specified temperature.

\section{Gasket compatibility:}

A study to be conducted to select the Gasket used for the connections to transfer of bulk solution during the manufacturing process. A bulk solution shall be prepared and stored with proposed gasket respective time points i.e. Initial (0 Hrs), $6 \mathrm{Hrs}, 12 \mathrm{Hrs}, 24 \mathrm{Hrs}, 48 \mathrm{Hrs}, 72 \mathrm{Hrs}$ and submitted for the evaluation of drug product CQA's i.e. Description, $\mathrm{pH}$, Assay, Related substances.

Ex. Silicon gasket, PTFE Gasket, EPDM Gasket.

Inference: Based on the study results, physical and chemical compatibility of the gasket with respective product and its hold time shall be proposed for further batches at specified temperature.

\section{Other MOC-Product contact parts of the equipment's \& line compatibility:}

A study to be conducted to select the MOC used during the manufacturing process. A bulk solution shall be prepared and stored with the coupons of proposed Silicon carbide (Used in Stirrer), Ceramic (Used in Filling pump) respective time points i.e. Initial ( $0 \mathrm{Hrs}$ ), $6 \mathrm{Hrs}, 12 \mathrm{Hrs}, 24 \mathrm{Hrs}, 48 \mathrm{Hrs}$, 72 Hrs and submitted for the evaluation of drug product CQA's i.e. Description, pH, Assay, Related substances. Based on the study results physical and chemical compatibility of the MOC with respective product and its hold time shall be proposed for further batches at specified temperature.

Selection of Sterilization method: A study to be conducted to select the sterilisation method and optimize the Sterilization cycle (if required) to obtain desired quality attributes of finished product.

\section{Effect of Autoclaving:}

The purpose of this study was to evaluate the thermal stability of formulation with heat input and time during the terminal sterilization process.

A batch to be formulated and solution was filled vials respectively, sealed and stoppered and were autoclaved at different Temperature \& Time (Ex. at $121^{\circ} \mathrm{C}$ for 15 minutes or 30 minutes or 45 minutes). The analytical results of the drug product CQA's i.e. Description, pH, Assay, Related substances of Autoclaved product in comparison with initial un-autoclaved sample if any abnormalities observed, it can be concluded that the product is sensitive terminal sterilization by autoclaving cannot be applied as a sterilization process as an alternative approach Aseptic filling shall be recommended. 


\section{pH Suitability Study:}

A study to be conducted to evaluate the stable $\mathrm{pH}$ range of the formulation to be maintained throughout the lifecycle. A bulk solution to be prepared with the proposed $\mathrm{pH}$ limits (Lower limit, Target Limit \& Higher Limit) and stored at different conditions like long term, Intermediate, Accelerated and evaluated for drug product CQA's i.e. Description, $\mathrm{pH}$, Assay, Related substances.

Inference: Based on the study results, $\mathrm{pH}$ limits of the respective product shall be proposed for further batches at specified temperature.

\section{Packaging materials selection studies:}

\section{Container Closure System Selection ${ }^{2,3}$ :}

Proposed container closure system shall be selected based on the available information on the packaging components of the RLD and on the laboratory development studies. Vial, Rubber Stopper, Seal.The closure was selected based on studies performed on the innovator and complies with the requirements of USP <381> and USP <87>. The Rubber stoppers has been qualified for use based on the results of biological, physiochemical, functionality and other characterization tests provided by the supplier's technical package.

Photo stability4: Photo stability studies are to be conducted to show that drug product is not light sensitive. A laboratoryscale batch to be prepared and exposed in a photo stability chamber according to ICH Q1B recommendations i.e. light providing an overall illumination 1.2 million lux hours and an integrated near ultraviolet energy of 200 watt hours/square meter. If the drug product CQA's of samples kept in immediate pack, marketed pack and dark control were well within the specification limits even after exposing to Light and UV of 1.2 million Lux hours and 200 watt hours/square meter respectively and is comparable to initial (control), it can be concluded that the product is photo stable.

Temperature cycling5: This study was conducted on the formulation to evaluate the effects of high and low temperature variations on the quality of the drug product.

This study was carried out by freezing the drug product at $20^{\circ} \mathrm{C}$ for 2 days followed by thawing at $40 \pm 2^{\circ} \mathrm{C} / 75 \pm 5 \% \mathrm{RH}$ for 2 days. This cycle was repeated for a total three times and after the completion of cycles, samples to be tested for drug product CQA's i.e. Description, pH, Assay and Related substances in comparison with initial results. If the entire drug product CQA's are well within the specification limits the product is stable for temperature extrusions as per the storage conditions mentioned in PIL.

Fill volume determination: Extractable volume Study was performed to determine the minimum fill volume required to withdraw nominal fill volume and shall be determined by Extractable volume study.

\section{Extractable Volume / Allowable Excess Volume Study6, 7 , 8:}

Fill volumes of all the presentations were adjusted according to the excess volume in injection as per USP, FDA guidance and to facilitate delivery of the labelled amount of the active ingredient to get desired pharmacological effect in comparison with RLD.

\section{Elemental impurities study ${ }^{9}$ :}

This study is to perform an elemental impurities analysis according to USP General Chapter .
The Elemental impurities; those were pose toxicological risks to patients without providing any therapeutic benefit. These impurities may be present in drug products from a variety of sources, such as elements intentionally added (e.g., catalysts) in the formation of the drug product components, those present in the ingredients used in the preparation of the drug product, those that leach into the drug substance and drug product from container closure systems, or, from manufacturing equipment.

This study is applicable for all three submission batches of product for US market and shall be evaluated at Long term conditions (Horizontal).

Acceptance criteria: All the parameters should comply as per USP ${ }^{9}$ and ICH Q3D 10

\section{Leachable study ${ }^{11}$ :}

This study is to evaluate the leachable and to evaluate any leachable impurities coming into the drug product from the packaging components of the drug products on longer duration of storage. Leachable (E/L) studies are critical to the identification and quantification of harmful leachable impurities, which could migrate, from pharmaceutical container closure systems, process equipment and packaging to contaminate pharmaceutical products.

A profile of extractable components must be obtained, via controlled extractable studies, in order to identify potential sources of Leachable such as antioxidants, plasticizers, dyes and metal catalysts. As pharmaceutical packaging, drug delivery systems and implantable medical devices can be extremely complex, with mixtures of plastic, polymer, rubber or glass materials, printed surfaces and coatings all utilized, it is critical that E/L studies are designed specifically for drug product and the container materials so that the risks associated with leachable impurities can be assessed.

This study is applicable for the one submission batch of product for US market and shall be evaluated at 3 month in Long term conditions (Horizontal).

Acceptance criteria: Test results should comply with the acceptance criteria as per USP general chapters.

\section{Pharmaceutical equivalency study:}

The objective of this document is to prove that test product is pharmaceutically Equivalent to Reference Listed Drug.

Pharmaceutical Equivalence is the condition in which drug products, containing the identical quantity of active substance (but not necessarily containing the same excipients), in an identical comparable dosage form, meets all applicable standards of Identical strength, quality, purity and potency.

This study is applicable for one of the submission batches of test product against single lot of reference product (RLD) for US market.

Acceptance criteria: All the physicochemical parameters of Test product should be comparable with that of Reference (RLD) product.

Finished product data will be considered as initial analysis data. Compare the in-house study results against the results of RLD samples.

Three submission batches and single lot of RLD shall be analyzed as a part of Pharmaceutical equivalency study. 


\section{References:}

1. Guidance for Industry M4: The CTD - Quality Questions and Answers/ Location Issues; June 2004

2. USP General Chapters on Elastomeric Closure for Injections $<381>$.

3. USP General Chapters on Biological Reactivity Tests - In Vitro<87>.

4. ICH Q1B; Photostability Testing of New Active Substances and Medicinal Products CPMP/ICH/279/95; January 1998.

5. PDA Technical Report No. 39, Revised 2007, (TR 39) ; Guidance for Temperature-Controlled Medicinal Products: Maintaining the
Quality of Temperature-Sensitive Medicinal Products Through the Transportation Environment.

6. USP General Chapters on Pharmaceutical dosage forms $<1151>$

7. USP General Chapters on Container content for injections <697>

8. Allowable Excess Volume and Labeled Vial Fill Size in Injectable Drug and Biological Products; FDA/CDER Guidance for Industry Pharmaceutical Quality/CMC; June 2015.

9. USP General Chapters on Elemental Impurities - Limits <232>.

10. ICH Harmonised Guideline for Elemental Impurities Q3D final version ; 22 March 2019.

11. USP General Chapters on Extractables and Leachables: <1663>, $<1664>$. 